\title{
Prevalence Of Different Age Groups That Under Go Extraction
}

Research Article

Sarojini Ramya Pillay ${ }^{1}$, Balakrishnan ${ }^{2 *}$, Remmiya Mary Varghese ${ }^{3}$

${ }^{1}$ Saveetha Dental College and Hospitals, Saveetha Institute of Medical and Technical Sciences (SIMATS), Saveetha University, Chennai, India.

${ }^{2}$ Senior Lecturer, Department of Oral and Maxillofacial Surgery, Saveetha Dental College and Hospitals, Saveetha Institute of Medical and Technical Sciences (SIMATS), Saveetha University, Chennai, India.

${ }^{3}$ Senior Lecturer, Department of Orthodontics, Saveetha Dental College and Hospitals, Saveetha Institute of Medical and Technical Sciences (SIMATS), Saveetha University,Chennai, India.

\section{Abstract}

The present study is aimed at analysing the prevalence of different age groups that undergo extraction. Tooth extraction is one of the dental treatments which should be considered the last option. A decrease in the number of teeth may result in poor dietary habits and deterioration of quality of life. The number of extracted teeth can serve as an indicator of socio-economic and oral hygiene level. Extraction of permanent teeth is performed for several reasons including dental caries, periodontal disease, orthodontic reasons, impacted teeth and root stumps.A retrospective cross-sectional study was conducted using the patient records from the Department of Oral maxillofacial surgery, Saveetha Dental College, Chennai from February 2019 to February 2020, and patients who had undergone extraction were selected by nonprobability sampling. Data was collected and then subjected to statistical analysis. Statistical Analysis was done with Microsoft Excel/2016 (Microsoft office 10) data spreadsheet was used and later exported to the Statistical Package for Social Science for Windows (version 20.0, SPSS Inc., Chicago Ill., USA). Results: A total of 22521 teeth were extracted in 9245 patients with the highest prevalence seen in the age group of 34-48 years old (28.1\%) and the least seen in the age group of $79-93$ years old $(0.6 \%)$. Males $(54.4 \%)$ have more teeth extracted than females $(45.6 \%)$. There was a statistically significant difference between gender and age of the patient undergoing extraction (0.000). This study concluded that the Prevalence of different age groups that undergo extraction seems to be high when compared to other literature. Considering the limitations of this study extensive research needs to be done to find the prevalence of different age groups that undergo extraction in a different study population. And to spread awareness on oral hygiene to minimise the number of tooth being extracted.

Keywords: Dental Caries; Extractions; Permanent Teeth; Primary Teeth Tooth Loss.

\section{Introduction}

Oral health is an essential component of general health as Sir William Osler stated that 'oral cavity is the mirror of general health' $[4,12]$. ' Dental extractions are mostly performed in dental clinics. Tooth extraction is defined as painless removal of the whole tooth or tooth root with minimal trauma to the investing tissues $[16,20]$ Chair positions of both the operator and patient have a pivotal role in determining the success of an extraction [25, 23]. The more common medical emergencies encountered in the dental chair include syncope which may arise due to anxiety of needle prick or dental extraction itself [7] he protocol followed by dentists until now is to stop antiplatelet drugs before dental procedures as they are known to affect coagulation and clot formation but the most recent recommendations favour the tooth extraction under continued antiplatelet or anticoagulation therapy [15] Dental mouth mirror is used for indirect vision and retraction while doing maxillary extraction [22] Tooth extractions or exodontia may be necessary to preserve or improve your dental health [28] and it appears to be mainly in response to the need for acute treatment and when there is a great accumulated need for treatment, patients increasingly selected extraction of teeth as the primary treatment rather than restorative procedures [31,

*Corresponding Author:

Balakrishnan,

Senior Lecturer, Department of Oral and Maxillofacial Surgery, Saveetha Dental College and Hospitals, Saveetha Institute of Medical and Technical Sciences (SIMATS), Saveetha University, Chennai, India.

E-mail: balakrishnarn.sdc@saveetha.com

Received: August 15, 2020

Accepted: August 26, 2020

Published: August 30, 2020

Citation: Sarojini Ramya Pillay, Balakrishnan, Remmiya Mary Varghese. Prevalence Of Different Age Groups That Under Go Extraction. Int J Dentistry Oral Sci. 2020;S4:02:0016:8487. doi: http://dx.doi.org/10.19070/2377-8075-SI02-040016

Copyright: Balakrishnan ${ }^{\circ}$ 2020. This is an open-access article distributed under the terms of the Creative Commons Attribution License, which permits unrestricted use, distribution and reproduction in any medium, provided the original author and source are credited. 
26] uncontrolled bleeding after extraction can be troublesome for both patient and the surgeon and can lead to serious consequences [12]. Local anaesthesia forms the backbone of pain control techniques in dentistry and are the safest and most effective drugs in all of medicine for the prevention and management of pain [26] during dental extraction as they cause local analgesic effect by inhibiting nerve conduction $[23,24]$ by doing so needle stick injury is one of the most common injuries which happens to a dentist. Infection $[12,31]$ control is a major part when performing extraction and a lack in this may lead to infection. Extractions of permanent and primary teeth are performed for several reasons such as dental caries [9] periodontal diseases [5] traumatic injuries, prosthetic considerations, orthodontic treatment, failed endodontic treatment and tooth impaction. However, the two major reasons for tooth loss worldwide are dental caries and periodontal disease [25]. Tooth loss is often associated with poor oral health which in order can affect the overall health of an individual [13]. Negative impact of tooth loss on oral health-related quality of life has been well documented [8]. Therefore, as dental practitioners, our main aim should be to prevent tooth loss. A number of epidemiological surveys have been carried out by various researchers in several countries across the world $[3,11,6]$. Majority of these studies have recommended that dental caries is the major reason for extraction of permanent teeth in younger age groups but as the age increases periodontal disease becomes the main reason for tooth loss. It is also seen that tooth extraction is considerably higher in irregular patients than regular patients because of dental caries [3]. Various studies conducted in different parts of India have also reported that dental caries and periodontal diseases account for the majority of tooth loss $[21,2,14,17]$. These studies suggested that tooth loss due to dental caries ranges from 19.8\% to $55.67 \%$ whereas periodontal disease accounts for $23.59 \%$ to $77 \%$ of tooth loss.

At present, limited data is available and the prevalence of different age groups that undergo extraction in India, particularly Chennai metropolitan city, tamilnadu.Availability of these data can be utilized for planning preventive oral health care policies in a given population. Hence, the aim of the present study was to investigate the Prevalence of different age groups that undergo extraction in Chennai.

\section{Materials and Methods}

Study design and setting This retrospective study examined the records of patients during February 2019-Febuary 2020 who underwent extraction at Saveetha Dental College, Chennai. Ethical approval was obtained from the Institutional Ethics Committee. The study population included patients who underwent extraction and were selected by means of non-probability sampling.

Data collection Saveetha Dental College's exclusive patient management software (DIAS, Dental Information Archiving Software) was used to identify 9245 patients from the hospital database who underwent extraction. Relevant data such as patient age, sex and tooth number was recorded. Data was verified by an external reviewer.

Inclusion Criteria: Patients of all age group patients underwentextraction of permanent teeth and primary teeth.

Statistical analysis: Data was recorded in Microsoft Excel/2016 (Microsoft office 10) and transferred to the Statistical Package for Social Science for Windows (version 20.0, SPSS Inc., Chicago Ill., USA) and subjected to statistical analysis. Chi square test was employed with a level of significance set at $\mathrm{p}<0.05$.

\section{Results And Discussion}

IDemographics The final dataset consisted of 9245 patients of Indian origin who underwent extraction. The mean age of patients who underwent extraction was 37.89 years (standard deviation $=18.512$ years). The patients average age ranged between 0 to 93 years in male and female.The patients were categorized into 6 age groups $0-17$ years, $18-33$ years, 34-48 years, 49-63 years, 64-78 years, 79-93 years The age group associated with greatest prevalence of extraction was $34-48$ years $(28.1 \% \mathrm{~N}=2600)$, followed by $18-33$ years old $(24.8 \% \mathrm{n}=2297), 49-63$ years $(21.9$ $\% \mathrm{~N}=2028), 0-17$ years $(16.2 \% \mathrm{~N}=1501), 64-78$ years old $(8.2 \%$ $\mathrm{n}=759)$ and the least was $79-93$ years old $(0.6 \% \mathrm{~N}=60)$ shown in [Figure 1] There was a male dominance as most of the patients who underwent extraction was male with a total of $5027(54.4 \%)$ extraction done and female with $4218(45.6 \%)$ shown in figure 2.

\section{Tooth type}

On analysing the type of teeth, molars were found to be most frequently extracted teeth $(70.9 \% \mathrm{n}=5814)$ followed by anterior teeth (15.5\% N=1274). Premolars were the least to be removed $(13.5 \% \mathrm{~N}=1110)$ shown in figure 3.

\section{Age vs gender}

There was a statistically significant difference between age and

Figure 1. Shows a Bar chart showing the distribution of age where the $\mathrm{X}$ axis represents age and $\mathrm{Y}$ axis represents frequency.The age group of 34-48 years had (28.1\%), followed by $18-33$ years old $(24.8 \%), 49-63$ years $(21.9 \%), 0-17$ years $(16.2 \%), 64-$ 78 years old $(8.2 \%)$ and the least was $79-93$ years old $(0.6 \%)$.

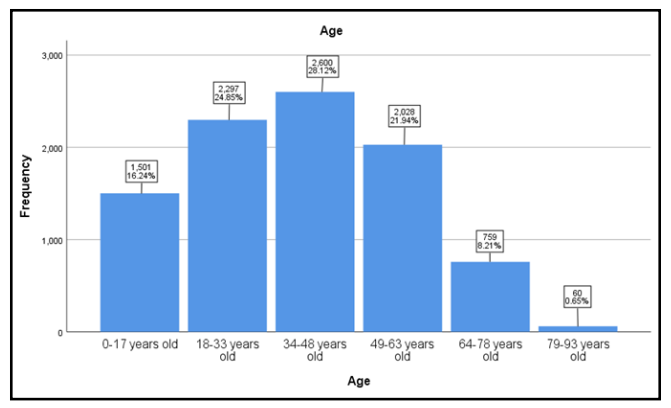


Figure 2. Bar chart showing the distribution of gender where $\mathrm{X}$ axis representing gender and $\mathrm{Y}$ axis representing frequency. Male had (54.4\%) extraction done and female with (45.6\%).

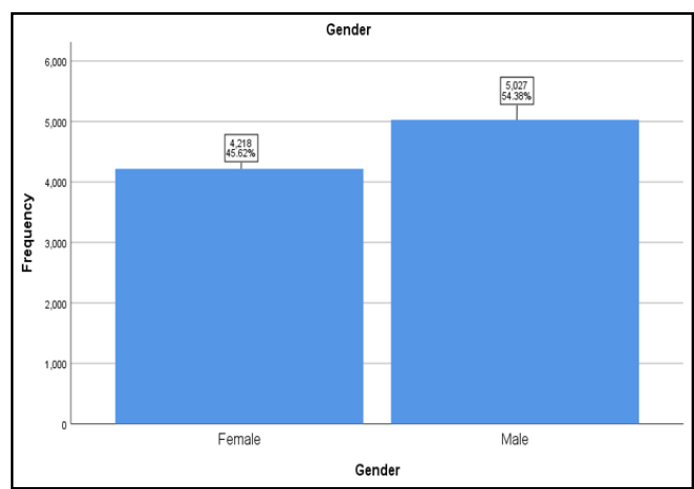

Figure 3. Shows a bar chart of the distribution of tooth type $\mathrm{X}$ axis shows the tooth type and $\mathrm{Y}$ axis shows the frequency. Molars had (70.9\%) followed by anterior teeth (15.5\%). Premolars were the least to be removed $(13.5 \%)$.

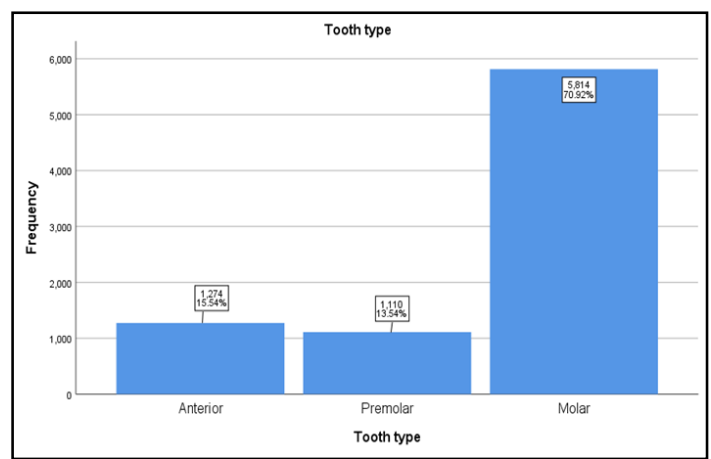

Figure 4. Shows a graphical representation of age vsgender.X axis represents the age and the $\mathrm{Y}$ axis represents the frequency of patients who underwent extraction.Blue denotes female and red denotes male.Majority of the male and female patients between the age group of 34-48 years old $(14.53 \%),(13.60 \%)$ respectively had extracted the maximum teeth.Pearson Chi square value-115.880,P value- 0.000 which is significant proving that maximum teeth extracted is between the age group of $34-48$ years old.

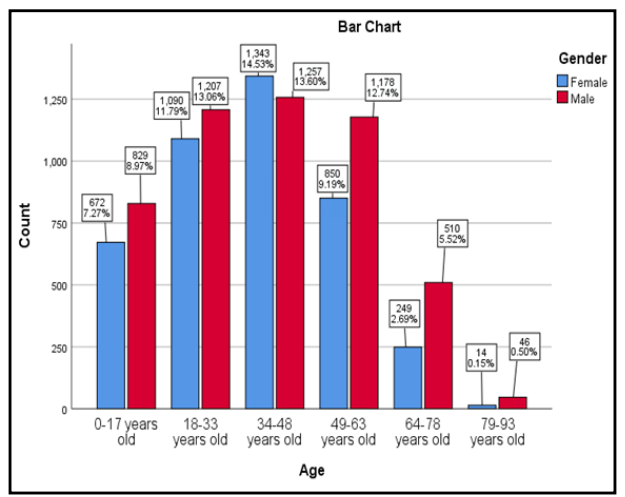

gender using chi square test $(p=0.000)$. The age group associated with greatest prevalence of extraction was 34-48 years where there was 1343 female and 1257 male,followed by 18-33 years old where male had 1207 and female had $1090,49-63$ years where male had 1178 and female had $850,0-17$ years where male had 829 and female $672,64-78$ years old where male had 510 and female 249 and the least was 79-93 years old where male had 46 and female had 14. Shown in figure 4.

This retrospective research was focused on chennai residents receiving treatment at saveetha dental college. All the data was included without a sorting process, no bias was expected in the selection of patients. The current study aims to shed light on the current scenario, where the preservation of natural teeth is considered to be one of the main aims of oral health care and therefore, the knowledge and understanding of the reasons influencing tooth extractions may provide valuable information for planning preventive oral health care strategies [27]. The World Health Organization (WHO) in its report identified good oral health as an indicator of good health and recommended various steps in order to improve oral health globally [25]. In this retrospective study more males had their tooth extracted than females this is contradicted by the literature literature done by [30] where male had $n=305$ and female $n=310$ the possible controversial findings could be explained by differences in the characteristics of the study population, immunological genetic factors, cultural beliefs.

According to [30] between the age group of 45-54 years old the highest percentage of tooth extracted was found (24.62\%) however in the current study the highest was found in the age group of 34-48 years old the possible reason could be socioeconomic characteristics of the patients. Also a study done by [18], found 
that the highest percentage of tooth extracted was found in 45-54 years old was found to be $(20.4 \%)$ possible reason could be the study population.

In the present molar teeth was found to be extracted more followed by anterior tooth and least was premolar and In a previous study done by [30] $\mathrm{t}$ was found that molars were most frequently extracted (35.4\%) This could be probably due to a several facts: (a) molars are the first permanent teeth to be erupted in oral cavity making them longest serving teeth; (b) they have a broader surface area with pit and fissures making them more susceptible to plaque accumulation and caries formation. $0.2 \%$ chlorhexidine gel and a eugenol-based paste on postoperative alveolar osteitis in patients having third molars extracted has been proven to be effective [10].

Considering that few studies evaluated reasons for teeth loss in Brazilians, our retrospective study may be useful in clinical dentistry and used as baseline data regarding preva- lence and reasons for teeth extractions in other populations; moreover, other prospective studies might be performed.Considering that few studies analyzed the prevalence of extraction of tooth in a prospective study, our retrospective study may be useful in clinical dentistry and used as baseline data regarding prevalence of teeth extractions in other populations moreover, other prospective studies might be performed.

\section{Conclusion}

Within the limitations of this study, it was found that the highest prevalence seen in the 34-48 years old group (28.1\%) and the least seen in the $79-93$ years old age group $(0.6 \%)$. Males $(54.4 \%)$ have more teeth extracted than females $(45.6 \%)$. Based on this finding, we recommend that preventive oral health strategies in Chennai should be designed to minimize the number of teeth being extracted. This fact should be taken into account in the planning of preventive programs and more attention should be given to the age of the targeted population.

\section{References}

[1]. Abhinav RP, Selvarasu K, Maheswari GU, Taltia AA. The Patterns and Etiology of Maxillofacial Trauma in South India. Ann Maxillofac Surg. 2019 Jan-Jun;9(1):114-117. PubmedPMID: 31293938.

[2]. Anand PS, Kuriakose S. Causes and patterns of loss of permanent teeth among patients attending a dental teaching institution in south India. J Contemp Dent Pract. 2009 Sep 1;10(5):E057-64. PubmedPMID: 19838611.

[3]. Cahen PM, Frank RM, Turlot JC. A survey of the reasons for dental extractions in France. J Dent Res. 1985 Aug;64(8):1087-93. PubmedPMID: 2862168.

[4]. Caldas AF Jr. Reasons for tooth extraction in a Brazilian population. Int Dent J. 2000 Oct;50(5):267-73. PubmedPMID: 15988885.

[5]. Chakraborty M, Thakkar RR, Swamy D, Kumar A, Badiyani SM, Dithi C, et al. Knowledge, Attitude, and Practices about Oral Hygiene Maintenance among Patients attending a Dental College in India. Int J Oral Care and Research. 2017;5(3):1-3.

[6]. Chestnutt IG, Binnie VI, Taylor MM. Reasons for tooth extraction in Scotland. J Dent. 2000 May;28(4):295-7. PubmedPMID: 10722904.

[7]. Christabel A, Anantanarayanan P, Subash P, Soh CL, Ramanathan M, Muthusekhar MR, et al. Comparison of pterygomaxillary dysjunction with tuberosity separation in isolated Le Fort I osteotomies: a prospective, multi-centre, triple-blind, randomized controlled trial. Int J Oral Maxillofac Surg. 2016 Feb;45(2):180-5. PubmedPMID: 26338075.

[8]. Gerritsen AE, Allen PF, Witter DJ, Bronkhorst EM, Creugers NH. Tooth loss and oral health-related quality of life: a systematic review and metaanalysis. Health Qual Life Outcomes. 2010 Nov 5;8:126. PubmedPMID:

\section{9.}

[9]. Vijayakumar Jain S, Muthusekhar MR, Baig MF, Senthilnathan P, Loganathan S, Abdul Wahab PU, et al. Evaluation of Three-Dimensional Changes in Pharyngeal Airway Following Isolated Lefort One Osteotomy for the Correction of Vertical Maxillary Excess: A Prospective Study. J Maxillofac Oral Surg. 2019 Mar;18(1):139-146. PubmedPMID: 30728705.

[10]. Jesudasan JS, Wahab PU, Sekhar MR. Effectiveness of $0.2 \%$ chlorhexidine gel and a eugenol-based paste on postoperative alveolar osteitis in patients having third molars extracted: a randomised controlled clinical trial. $\mathrm{Br} \mathrm{J}$ Oral Maxillofac Surg. 2015 Nov;53(9):826-30. PubmedPMID: 26188932.

[11]. Kay EJ, Blinkhorn AS. The reasons underlying the extraction of teeth in Scotland. Br Dent J. 1986 Apr 19;160(8):287-90. PubmedPMID: 3457583.

[12]. Kumar S, SnehaS. 'knowledge and awareness regarding antibiotic prophylaxis for infective endocarditis among undergraduate dental students', asian Journal of Pharmaceutical and Clinical Research.2016; 154. doi: 10.22159/ ajpcr.2016.v9s2.13405.

[13]. Mack F, Schwahn C, Feine JS, Mundt T, Bernhardt O, John U, et al. The impact of tooth loss on general health related to quality of life among elderly Pomeranians: results from the study of health in Pomerania (SHIP-O). Int J Prosthodont. 2005 Sep-Oct;18(5):414-9. PubmedPMID: 16220807.

[14]. Manekar VS, Kende P, Kulkarni S. Tooth mortality: an analysis of reasons underlying the extraction of permanent teeth. World J Dent. 2015;6(2):936.

[15]. Marimuthu M, Andiappan M, Wahab A, Muthusekhar MR, Balakrishnan A, Shanmugam S. Canonical Wnt pathway gene expression and their clinical correlation in oral squamous cell carcinoma. Indian J Dent Res. 2018 MayJun;29(3):291-297. PubmedPMID: 29900911.

[16]. Mathur MN, Nath S. Tooth mortality. An analysis of extraction cases. J Indian Dent Assoc. 1968 Aug;40(8):213-5.Pubmed PMID: 5247555.

[17]. Migliorati C, Panagakos F, editors. Diagnosis and Management of Oral Lesions and Conditions: A Resource Handbook for the Clinician. BoD-Books on Demand; 2014 Feb 19.

[18]. Montandon A, Zuza E, Toledo BE. Prevalence and reasons for tooth loss in a sample from a dental clinic in Brazil. Int J Dent. 2012;2012:719750. PubmedPMID: 22973312.

[19]. Kumar S. Relationship between dental anxiety and pain experience during dental extractions. Asian Journal of Pharmaceutical and Clinical Research. 2017;10(3):458-.

[20]. Kumar S, Rahman RE. Knowledge, awareness, and practices regarding biomedical waste management among undergraduate dental students. Asian Journal of Pharmaceutical and Clinical Research. 2017;10(8):341.

[21]. Nair M, Jeevanandan G, Vignesh R, Subramanian EM. Comparative evaluation of post-operative pain after pulpectomy with k-files, kedo-s files and mtwo files in deciduous molars-a randomized clinical trial. Brazilian Dental Science. 2018 Oct 24;21(4):411-7.

[22]. Packiri S, Gurunathan D, Selvarasu K. Management of Paediatric Oral Ranula: A Systematic Review. J ClinDiagn Res. 2017 Sep;11(9):ZE06-ZE09. PubmedPMID: 29207849

[23]. Patil SB, Durairaj D, Suresh Kumar G, Karthikeyan D, Pradeep D. Comparison of Extended Nasolabial Flap VersusBuccal Fat Pad Graft in the Surgical Management of Oral Submucous Fibrosis: A Prospective Pilot Study. J Maxillofac Oral Surg. 2017 Sep;16(3):312-321. PubmedPMID: 28717289.

[24]. Patturaja K, Pradeep D. Awareness of Basic Dental Procedure among General Population. Research Journal of Pharmacy and Technology. 2016 Sep $1 ; 9(9): 1349$.

[25]. Petersen PE. The World Oral Health Report 2003: continuous improvement of oral health in the 21st century--the approach of the WHO Global Oral Health Programme. Community Dent Oral Epidemiol. 2003 Dec;31Suppl 1:3-23. PubmedPMID: 15015736.

[26]. Rahman RE, Mp SK. Knowledge, attitude, and awareness of dental undergraduate students regarding human immunodeficiency virus/acquired immunodeficiency syndrome patients. Asian J Pharm Clin Res [Internet]. 2017;10(5):175-80.

[27]. Rakocz M, Mazar A, Varon D, Spierer S, Blinder D, Martinowitz U. Dental extractions in patients with bleeding disorders. The use of fibrin glue. Oral Surg Oral Med Oral Pathol. 1993 Mar;75(3):280-2. PubmedPMID: 8469534.

[28]. Rao TD, Kumar MS. Analgesic efficacy of paracetamolvs ketorolac after dental extractions. Research Journal of Pharmacy and Technology. 2018 Aug $1 ; 11(8): 3375-9$.

[29]. Kumar MS. Evaluation of Various Factors for Extraction of Permanent Teeth in a Dental College.

[30]. Shah A, Faldu M, Chowdhury S. Reasons for extractions of permanent teeth in western India: A prospective study.

[31]. Sweta VR, Abhinav RP, Ramesh A. Role of Virtual Reality in Pain Perception of Patients Following the Administration of Local Anesthesia. Ann Maxillofac Surg. 2019 Jan-Jun;9(1):110-113. PubmedPMID: 31293937 